University of Nebraska - Lincoln

DigitalCommons@University of Nebraska - Lincoln

Faculty Publications, Department of Psychology

Psychology, Department of

January 2007

\title{
Personal Values as a Mediator Between Parent and Peer Expectations and Adolescent Behaviors
}

\author{
Laura M. Padilla-Walker \\ School of Family Life, Brigham Young University \\ Gustavo Carlo \\ University of Nebraska-Lincoln, carlog@missouri.edu
}

Follow this and additional works at: https://digitalcommons.unl.edu/psychfacpub

Part of the Psychiatry and Psychology Commons

Padilla-Walker, Laura M. and Carlo, Gustavo, "Personal Values as a Mediator Between Parent and Peer Expectations and Adolescent Behaviors" (2007). Faculty Publications, Department of Psychology. 297. https://digitalcommons.unl.edu/psychfacpub/297

This Article is brought to you for free and open access by the Psychology, Department of at DigitalCommons@University of Nebraska - Lincoln. It has been accepted for inclusion in Faculty Publications, Department of Psychology by an authorized administrator of DigitalCommons@University of Nebraska - Lincoln. 
Published in Journal of Family Psychology, $21: 3$ (2007), pp. 538-541; doi: 10.1037/0893-3200.21.3.538

Copyright (C) 2007 American Psychological Association. Used by permission. "This article may not exactly replicate the final version published in the APA journal. It is not the copy of record." http://www.apa.org/journals/fam/

Submitted April 24, 2006; revised October 30, 2006; accepted: November 3, 2006.

\title{
Personal Values as a Mediator Between Parent and Peer Expectations and Adolescent Behaviors
}

\author{
Laura M. Padilla-Walker \\ School of Family Life, Brigham Young University \\ Gustavo Carlo \\ Department of Psychology, University of Nebraska-Lincoln
}

\begin{abstract}
The current study examined the mediating role of adolescents' personal values on the relation between maternal and peer expectations for prosocial behaviors and adolescents' self-reported prosocial and antisocial behaviors. One hundred thirty-four adolescents (mean age $=16.22$ years, $54 \%$ girls) completed measures of their own values and behaviors, as well as their perceptions of the positive expectations that their mother and their best friend(s) had for their (the adolescents') prosocial behaviors. Stepwise regression analyses suggested that adolescents' personal prosocial values mediated the relation between adolescents' perceptions of both maternal and peer expectations and adolescents' prosocial behaviors. In addition, for boys, perceptions of positive peer expectations were directly and negatively related to antisocial behaviors. The current study has important implications for parents, educators, and practitioners who are concerned about promoting adolescents' positive behaviors and discouraging negative behaviors.
\end{abstract}

Keywords: parent and peer expectations, personal values, prosocial behaviors

One useful way to assess the relative role of parents and peers in adolescent development is to assess the adolescent's own perceptions of the values and expectations of others (Berndt, Miller, \& Park, 1989; Brown, Lohr, \& McClenahan, 1986). Adolescents' conformity to the values and expectations of peers rises during early adolescence, whereas conformity to parental expectations declines. As adolescents reach middle adolescence, however, conformity to both parents and peers is on the decline, and adolescents' actions are based much more on behavioral autonomy, or the adolescents' own values and expectations for themselves (Steinberg \& Silverberg, 1986). Research has also found that values often act as a mediator between cognitions and behaviors (see McGillicuddy-De Lisi \& Sigel, 1995), such that cognitions or perceptions influence values, which in turn, influence behaviors. Thus, the current study explored the possibility that adolescents' personal prosocial values mediated the relation between perceptions of maternal-peer expectations for prosocial behaviors and adolescents' self-reported prosocial and antisocial behaviors.

Although a desire for autonomy is pronounced during adolescence, so is a desire for relatedness, or adolescents' need

Support was provided to Gustavo Carlo by National Science Foundation Grant BNS 0132302. Data for this project were gathered while Laura M. Padilla-Walker was at the University of Nebraska-Lincoln. We thank the students and teachers of Lincoln Southeast High School for their cooperation, especially Rob McEntarffer.

Corresponding author: Laura M. Padilla-Walker, 2097 JFSB, School of Family Life, Brigham Young University, Provo, UT 84602 Email: laura walker@byu.edu. to feel connected to those they care about (Grolnick \& Farkas, 2002). Two prominent sources of relatedness are parents and peers. Individuals' need to be connected to others helps to guide their socially acceptable and unacceptable behavior, and looking to the behavioral expectations of others as a marker for personal behavior is one indicator of connectedness. Thus, perceived expectations of others are an important facet to explore when examining prosocial and antisocial behaviors. Despite the fact that there is much research suggesting that parent and peer expectations are related to antisocial behaviors (see Nash, McQueen, \& Bray, 2005), there is little research examining the role of perceived expectations on adolescents' prosocial behaviors. Although the majority of research examining the role of peers focuses on the impact of negative peer behaviors and expectations on adolescents' antisocial behaviors (e.g., Farrell \& White, 1998; Brown et al., 1986) found that peer pressure was more consistently related to adolescents' positive than negative behaviors. However, positive behaviors in Brown et al.'s study were limited to pressure to not engage in negative behaviors (such as drug use and sexual activity) and pressure to get along with parents and to do well academically. There is a relative paucity of research that generally examines the role of positive parent or peer behavioral expectations in adolescents' prosocial behaviors.

Although direct paths from perceived expectations to behaviors were examined, given the growing autonomy of middle adolescence and prior research on the mediating role of values (see McGillicuddy-De Lisi \& Sigel, 1995), adolescents' 
personal values were also examined as a possible mediator between adolescents' perceptions of behavioral expectations and adolescents' behaviors. Because of the dynamic nature of the relation between parent and peer influences on adolescent development, it was expected that both parent and peer expectations would be related to behaviors. However, given the heightened importance of peers during adolescence and research suggesting that adolescents' susceptibility to peer pressure toward misconduct peaks in middle adolescence (Sim \& Koh, 2003), it was expected that peer expectations would have a stronger influence than maternal expectations on adolescents' antisocial behaviors, especially for boys, who are more susceptible than girls to peer pressure toward misconduct.

\section{Method}

\section{Participants and Procedure}

One hundred thirty-four adolescents (mean age $=16.22$ years, $S D=1.27 ; 54 \%$ female; $84 \%$ European American) who attended a public high school in the Midwestern region of the United States participated in the study. Sixty-eight percent of the adolescents reported living with both of their parents. This sample is representative of the demographics in this area.

Of the 45 classrooms that agreed to participate $(69 \%$ response rate), 8 classrooms were randomly selected to complete the study. Of the 140 students selected, 134 obtained active parental consent and agreed to participate. Students completed the survey in their classroom.

\section{Measures}

Expectations and personal values. Adolescents' personal values and perceived maternal and peer expectations for prosocial behaviors were assessed using a slightly modified version of the honesty, kindness, and fairness subscales of the Values in Action Inventory of Strengths, the psychometric properties of which are internally consistent and reported elsewhere (Peterson \& Seligman, 2004). Personal values $(\alpha=.88)$ were assessed as follows: Adolescents answered 13 questions (e.g., "It is important to tell the truth, even if it hurts") on a 15 scale $(1=$ strongly disagree, $5=$ strongly agree $)$. Adolescents also answered slightly reworded questions ("My mother/ friends expect me to" added to the stem) to assess maternal ( $\alpha$ $=.82)$ and peer $(\alpha=.88)$ expectations for the adolescents' prosocial behaviors (26 items).

Behavior measures. Prosocial behaviors were assessed with a shortened scale commonly used with adolescents (Rushton, Chrisjohn, \& Fekken, 1981). Ten items $(\alpha=.82)$ regarding the frequency of adolescents' prosocial behaviors (e.g., "I have helped someone who needed my help, even when it was inconvenient to me") were rated on a 5 -point scale $(1=$ never, $5=$ very often). Antisocial behaviors were assessed using a shortened subscale of the Youth Version of the Child Behavior Checklist (Achenbach, 1991). Nine items $(\alpha=.84)$ regarding delinquent behaviors (e.g., "I cut classes or skip school," "I lie or cheat") were rated on a 5 -point scale $(1=$ never $=5$ very often $)$.

\section{Results}

\section{Descriptive Statistics}

A number of univariate analyses of variance (ANOVAs) were conducted to determine whether the primary variables of interest differed as a function of adolescent gender. Of the five ANOVAs conducted, three were statistically significant. Girls $(M=3.79, S D=.52)$ reported higher peer expectations than boys $(M=3.31, S D=.60), F(1,132)=24.54, p=.001$; girls $(M=4.01, S D=0.49)$ reported greater importance of personal values than boys $(M=3.65, S D=0.69), F(1,132)=12.31, p$ $=.001$; and girls $(M=3.39, S D=0.57)$ reported higher frequency of prosocial behaviors than boys $(M=3.01, S D=$ $0.79), F(1,132)=10.21, p=.003$. As a result, all subsequent analyses were conducted separately for girls and boys.

\section{Stepwise Multiple Regression Analyses of Variables Predict- ing Adolescents' Behaviors}

For all analyses, maternal and peer expectations were entered in Step 1. Personal values were then added in Step 2. In order to assess mediation, three steps must be taken. First, establishing a relation between the independent variable and the mediator; second, establishing a relation between the independent variable and the dependent variable; and third, establishing a relation between the mediator and the dependent variable after controlling for the independent variable. In addition to following these three steps, we also conducted the Sobel test, which provides a direct test of simple mediation by comparing the strength of the indirect effect to the null hypothesis (Preacher \& Hayes, 2004). Although the first step of mediation - that is, was there a relation between maternal and peer expectations (independent variables) and personal values (mediator) - was not the focus of this study and is therefore not discussed in detail, these relations were examined and found to be statistically significant, warranting exploration of mediation.

Prosocial behaviors. Table 1 presents regression analyses predicting prosocial behaviors for both girls and boys. For girls, maternal and peer expectations accounted for a statistically significant portion of explained variance in Step 1. In Step 2, adding personal values resulted in an $8 \%$ increase in the proportion of explained variance, and maternal expectations and peer expectations were no longer uniquely contributing. Further, in order to assess the significance of the indirect effect of expectations on prosocial behaviors, the Sobel test was used and suggested that adolescents' personal values mediated the relation between both maternal $($ Sobel $=3.84$, $p<.001)$ and peer $($ Sobel $=4.21, p<.001)$ expectations and girls' prosocial behaviors. For boys, maternal and peer expectations accounted for a statistically significant portion of explained variance in Step 1. In Step 2, adding personal values resulted in a $13 \%$ increase in the proportion of explained variance, and maternal expectations and peer expectations were no longer uniquely contributing. Further, in order to assess the significance of the indirect effect of expectations on prosocial 
Table 1

Stepwise Multiple Regression Analyses of Variables Predicting Adolescents'Prosocial and Antisocial Behaviors

\begin{tabular}{|c|c|c|c|c|}
\hline Variable & \multicolumn{2}{|c|}{ Prosocial behaviors } & \multicolumn{2}{|c|}{ Antisocial behaviors } \\
\hline \multicolumn{5}{|l|}{ Step 1} \\
\hline Peer expectations & $.35 * *$ & $.26^{*}$ & -.23 & $-.47 * * *$ \\
\hline Multiple $R^{2}$ & $.27 * * *$ & $.30 * * *$ & $.19 * *$ & $.26^{* * *}$ \\
\hline \multicolumn{5}{|l|}{ Step 2} \\
\hline Peer expectations & .16 & -.04 & -.18 & $-.47 * *$ \\
\hline Personal values & $.40 * *$ & $.57 * *$ & -.10 & -.01 \\
\hline Multiple $R^{2}$ & $.35 * * *$ & $.43 * * *$ & $.20 * *$ & $.26^{* *}$ \\
\hline
\end{tabular}

Note. All beta weights are standardized.

$* p<.05$. ** $p<.01 . * * * p<.001$.

behaviors, the Sobel test was used and suggested that adolescents' personal values mediated the relation between both maternal (Sobel $=4.31, p<.001)$ and peer $($ Sobel $=4.87, p<$ $.001)$ expectations and boys' prosocial behaviors.

Antisocial behaviors. Table 1 presents regression analyses predicting antisocial behaviors for both girls and boys. For girls, maternal expectations accounted for a statistically significant portion of explained variance in Step 1. In Step 2, adding personal values did not result in an increase in the proportion of explained variance. For boys, peer expectations accounted for a statistically significant portion of explained variance in Step 1. In Step 2, adding personal values did not result in an increase in the proportion of explained variance.

\section{Discussion}

The purpose of the current study was to examine the mediating role of personal prosocial values on the relation between maternal-peer expectations for prosocial behaviors and adolescents' self-reported prosocial and antisocial behaviors. Results suggested that expectations were indirectly related to adolescents' prosocial behaviors, and the relation was mediated by adolescents' personal prosocial values. This not only suggests the importance of positive behavioral expectations but also highlights the importance of adolescents' personal values. Findings extend existing literature by examining the indirect effects of both parents and peers on adolescents' prosocial behaviors and suggest that perceptions of the expectations of others are importantly related to prosocial behaviors, primarily by the way expectations influence autonomously chosen values (Steinberg \& Silverberg, 1986).

Although adolescents' personal values mediated the relation between expectations and prosocial behaviors, this was not the case for antisocial behaviors. It is possible that the pathways to prosocial and antisocial behaviors are different, which is consistent with research suggesting the particular importance of parental monitoring and consistent discipline in deterring children's antisocial behaviors (Patterson, Reid, \&
Dishion, 1992). However, future research is needed to more fully understand how the pathways to prosocial and antisocial behaviors might differ.

Variables associated with adolescents' antisocial behaviors varied as a function of gender. Although the regression predicting antisocial behaviors for girls was statistically significant, the only variable even marginally related to girls' antisocial behaviors was maternal expectations. In contrast, boys who perceived higher peer expectations for prosocial behaviors (but not maternal expectations) reported participating in fewer antisocial behaviors. These findings are consistent with research suggesting that boys are more influenced by peers than are girls, especially in terms of peer pressure toward misconduct ( $\operatorname{Sim} \&$ Koh, 2003). Thus, it is possible that the positive role of peers is more salient for boys and serves as somewhat of a protective factor against antisocial behaviors.

There were a number of limitations in the current study. First, the use of single-reporter data may be seen as a limitation. It will be important for future research to examine actual expectations of others in order to better assess external validity and to reduce the possibility of social desirability demands. Second, replication of the present findings using multiple methods would be useful, especially given the necessary modification of measures in the current study. Third, future research should examine a more heterogeneous population. For example, it will be important to examine how parental expectations may differ in blended, divorced families, or ethnic minority families, where there may be more disparity between parental messages. Given that rates of self-reported antisocial behaviors were generally low and the sample was from a normative (nonclinical) population, it will also be important for future research to examine this process in a more diverse sample to improve clinical relevance. And fourth, direction of effects could not be determined because of the cross-sectional nature of the current study. Longitudinal research should be conducted to gain greater confidence in this developmental process. For example, future research should examine the degree to which adolescents choose friends who have expecta- 
tions similar to parental expectations and established personal values or the degree to which adolescents' own personal values are adjusted as a function of potentially changing expectations from parents and peers. Given the complexity of this process, it will be important for future research to focus on how parent and peer influences simultaneously and dynamically influence adolescent development over time. Despite these limitations, this study has important implications for intervention that attempts to shift adolescents' focus from perceived peer pressure toward antisocial behaviors, to perceived peer pressure toward prosocial behaviors.

\section{References}

Achenbach, T. M. (1991). Manual for the Child Behavior Checklist/4-18 and 1991 profile. Burlington: University of Vermont, Department of Psychiatry.

Berndt, T. J., Miller, K. E., \& Park, K. (1989). Adolescents' perceptions of friends' and parents' influence on aspects of their school adjustment. Journal of Early Adolescence, 9, 419-435.

Brown, B. B., Lohr, M. J., \& McClenahan, E. L. (1986). Early adolescents' perceptions of peer pressure. Journal of Early Adolescence, 6, 139-154.

Farrell, A., \& White, K. (1998). Peer influences and drug use among urban adolescents: Family structure and parent-adolescent relationship as protective factors. Journal of Counseling and Clinical Psychology, 66, 248-258.
Grolnick, W. S., \& Farkas, M. (2002). Parenting and the development of children's self-regulation. In M. H.Bornstein (Ed.), Handbook of parenting: Vol. 5. Practical issues in parenting (2nd ed., pp. 89-110). Mahwah, NJ: Erlbaum.

McGillicuddy-De Lisi, A. V., \& Sigel, I. E. (1995). Parental beliefs. In M. H.Bornstein (Ed.), Handbook of parenting: Vol. 3. Status and social conditions of parenting (pp. 333-358). Mahwah, NJ: Erlbaum.

Nash, S. G., McQueen, A., \& Bray, J. H. (2005). Pathways to adolescent alcohol use: Family environment, peer influence, and parental expectations. Journal of Adolescent Health, 37, 19-28.

Patterson, G. R., Reid, J. B., \& Dishion, T. J. (1992). A social interactional approach: Vol. 4. Antisocial boys. Eugene, OR: Castalia.

Peterson, C., \& Seligman, M. E. P. (2004). Character strengths and virtues: A handbook and classification. New York: Oxford University Press.

Preacher, K. J., \& Hayes, A. F. (2004). SPSS and SAS procedures for estimating indirect effects in simple mediation models. Behavior Research Methods, Instruments, \& Computers, 36, 717-731.

Rushton, J. P., Chrisjohn, R. D., \& Fekken, G. C. (1981). The altruistic personality and the self-report altruism scale. Personality and Individual Differences, 2, 1-11.

Sim, T. N., \& Koh, S. F. (2003). A domain conceptualization of adolescent susceptibility to peer pressure. Journal of Research on Adolescence, 13, 57-80.

Steinberg, L., \& Silverberg, S. B. (1986). The vicissitudes of autonomy in early adolescence. Child Development, 57, 841-851. 